\title{
Responses of Marsilea minuta L. to Cadmium Stress and Assessment of Some Oxidative Biomarkers
}

\author{
Kingsuk Das $^{1 *}$, Chiranjib Mandal ${ }^{1}$, Nirmalya Ghosh $^{1}$, Narottam Dey ${ }^{2}$, Malay Kumar Adak ${ }^{*} \#$ \\ ${ }^{1}$ Plant Physiology and Plant Molecular Biology Research Unit, Department of Botany, University of Kalyani, \\ Kalyani, India \\ ${ }^{2}$ Department of Biotechnology, Visva Bharati, Santiniketan, India \\ Email: ${ }^{\text {mkadak09@gmail.com }}$
}

Received 20 March 2014; revised 19 April 2014; accepted 29 April 2014

Copyright (C) 2014 by authors and Scientific Research Publishing Inc.

This work is licensed under the Creative Commons Attribution International License (CC BY). http://creativecommons.org/licenses/by/4.0/

(c) (i) Open Access

\section{Abstract}

In a hydroponic based experiment, the Cd toxicity is monitored with some cellular responses of Marsilea plant. Initially, plants were grown under varying concentrations $(0,50,100$ and $200 \mu \mathrm{M}$ of Cd) of cadmium (Cd) with supplementation of $2 \mathrm{mM}$ spermidine (Spd). The oxidative stress developed by Cd overaccumulation was measured with fall in Relative Growth Rate (RGR) by 27.11\% to $59.83 \%$ growth reduction over control under varying $\mathrm{Cd}$ treatments. The retrieval of RGR was recovered by 1.59 folds as compared to the highest concentration of $\mathrm{Cd}(200 \mu \mathrm{M})$ when plants were fed with Spd. A concomitant degradation of chlorophyll was recorded in dose-dependant manner, however, the retrieval was not much pronounced with Spd. On the contrary, the nonoxidant thiol had borne more clarity with ongoing Cd concentration and appeared to be $40.51 \%$ increase maximally for GSH: GSSG at the highest concentration of Cd. Spd has minimized the ratio by $27.4 \%$. The recovery of osmotic turgidity was indexed with a sharp rise in glycine betaine by 3.86 folds maximum at the highest concentration of Cd over control which declined by $30.9 \%$ with Spd. Another cellular response of treated plants was more evident from their isozymic profiles with regard to superoxide dismutase (SOD), catalase (CAT), guaiacol peroxidase (GPX). The intensity of protein expression was significantly variable but not in band numbers as evident from Cd treated plants. In vitro enzyme assay of catalase showed as declining trend within the limit of $33.13 \%$ to $43.22 \%$ which was reported by 1.45 folds when Spd was applied. Therefore, from the present study, the cellular responses of Marsilea plant which showed compatibility for their expression with Cd toxicity could be hypothesized as a case of bioindication.

\footnotetext{
"Malay Kumar Adak and Kingsuk Das contributed equally.
}

"Corresponding author. 
Keywords

\section{Cadmium Toxicity, Marsilea minuta, Bioindicators}

\section{Introduction}

Cadmium (Cd), a divalent cation is widely accepted as an effective pollutant with its higher uptake, translocation and thus its bioavailability in plants. Cd with its wider availability in soil, particularly, in the industrial zones frequently poses a threat for the sustainability of plant species. Cd is not behaved as a typical redox metal, still, after absorption by the roots following translocation through the aerial parts, it affects the whole cellular metabolisms. Through the retardation of ion homoeostasis in roots, Cd becomes more vulnerable at the leafy shoots for inhibition of photosynthesis, non-functioning of stomatal behavior, inhibition of respiratory flux, inadequate photoperiodic responses and fall in growth that results in less yield [1]. Apparently, a number of physiological symptoms have been obvious for Cd toxicity in plants including chlorosis, mortling of veins, browning of the root tips, drying of shoot apex, immature defoliation etc. At the cellular level, otherwise, Cd is more offered as a pro-oxidant, since a series of reactive oxygen species (ROS) are accumulated in excess in affected tissues. Inhibitions of electron transport between photosystems and other electron transport pathways, Cd interferes in proper oxidation of oxygen into water and results reduction of oxygen into various ROS. Still, a number of plant species are frequently reported to withstand the Cd toxicity despite excess accumulation in the tissue level without altering the growth significantly. Commonly those species are regarded as Cd hyperaccumulator and are listed predominantly from angiosperm species [2]. Since oxidative stress is a confirmatory index for Cd toxicity, higher plants which are quite common for biomonitoring and ecotoxicological determination for $\mathrm{Cd}$ toxicity. Therefore, monitoring of Cd phytotoxicity could employ the anti-oxidation pathways induced in concerned plant species. Cd with its fairly solubility in water is also regarded as relevant pollutant in water bodies and thus hydrophytes are more prone to susceptible of Cd toxicity. Most of the cases, food chain contamination and its magnification by Cd start from such hydrophytic species, particularly in the industrial zone [3].

In comparison to higher plants, non-angiospermic species are less explored in this regard where accumulation of heavy metals is tolerated with improved physiological traits for their sustenance. Non-vascular plants mostly pteridophytic species are very often referred to have their wider tolerance under heavy metal stress and thereby suggested as hyperaccumulator species. As example, Pteris is quite common to hyperaccumulate a few heavy metals like arsenic (As), nickel $(\mathrm{Ni})$, cadmium $(\mathrm{Cd})$, lead $(\mathrm{Pb})$, zinc $(\mathrm{Zn})$ etc. [4]. With this fern species, the other aquatic fern species have also been attempted to exploit their hyperaccumulation property if any. In earlier communication, Salvinia natans L., a commonly occurring aquatic fern recorded significant accumulation of metal in its biomass with wider range. The distribution of metal in intercellular spaces had shown its strategy to avoid contamination. Thus, in continuation we report the potential of Marsilea minuta L., another aquatic fern species which has been chosen to decipher the impact of Cd mediated oxidative stress under Cd toxicity. The cellular responses were taken in the present experiment in terms of compatible solutes like glycine-betaine, antioxidative enzymes including guaiacol peroxidase, catalase and superoxide dismutase which were employed to assess the potentials of Marsilea plant.

It is quite obvious that cellular responses are modulated under metal toxicity or any other abiotic stresses in compulsion with any signals due to some elicitors. A number of chemical compounds either endogenous in origin or applied exogenously are reported to be inductive in metal tolerance in plants. Out of those polyamine might be an effective moiety in consideration of mitigation of oxidative stress. Oxidative stress with regards to polyamine metabolism has been dealt in new aspect though not fully understood the regulation of ROS generation and its concommiant mitigation by polyamine application has defolded in many aspects of oxidative stress sensitivity in many plant species [5]. Marsilea minuta L., a tropical fern species has extended their adaptability in contaminated water bodies where Cd appears to be one of the serious pollutants. Whatever the possibility, the amplification of cellular responses adhered to oxidative sensitivity out of metal stress in any hyperaccumulating species has been wider opportunity for phytoremediatory aspects also.

Therefore, here in, we briefly summarize the impact of spermidine application in interaction of Cd mediated oxidative stress in Marsilea plants. In the present communication, we, perhaps the first time to report the Mar- 
silea plant, a fern species reacted with polyamine (spermidine: a triamine) under Cd stress with the illustration of some cellular responses. Polyamines play a significant role in modulating different types of abiotic stresses [6]. We assume that the Marsilea plant and the exercised physiological parameters could be defolding the aspects of pointing biomarker for $\mathrm{Cd}$ rich soil. Therefore, a plant species, particularly, from non-angiospermic fern groups would be a new material for biomonitoring purposes in Cd affected soil. Moreover, Marsilea species which is abundantly and widely grown vegetation in tropical atmosphere could also be hypothesized to be potential material for Cd hyeraccumulation.

\section{Materials and Methods}

\subsection{Plant Growth and Treatment}

Marsilea minuta L., the experimental material was collected from the industrial belts of Kalyani, Nadia, W.B., India. The plants were thoroughly washed and were grown for 7 days in Hoagland's solution.Thereafter, plants were supplemented with varying concentrations $(0 \mu \mathrm{M}, 50 \mu \mathrm{M}$ and $100 \mu \mathrm{M}$ and $200 \mu \mathrm{M})$ of cadmium chloride dissolved in the same solution in different sets. Moreover, in another one set, $2 \mathrm{mM}$ spermidine was supplemented with $200 \mu \mathrm{M}$ of $\mathrm{CdCl}_{2}$ solution. The plants were then grown for 7 days in growth chamber $\left(37^{\circ} \mathrm{C} \pm 1^{\circ} \mathrm{C}\right)$, $85 \%$ relative humidity and $14 \mathrm{~h}$ light (irradiance $72-80 \mu \mathrm{M} / \mathrm{m}^{2} / \mathrm{s}$ ) and $10 \mathrm{~h}$ in dark. The nutrient solution was changed at every two day. On completion of the incubation period, the plants were sampled and frozen in liquid nitrogen and stored at $-80^{\circ} \mathrm{C}$ for further biochemical assays.

\subsection{Determination of Relative Growth Rate}

For the analysis of relative growth rate, the plants were recovered from Cd doses, washed thoroughly with deionized water and made completely dry in hot air oven under $80^{\circ} \mathrm{C}$ for 5 days for constant weights. On completion, the dried plants were recorded weights and computed relative growth rate (RGR) following [7].

\subsection{Determination of GSH and GSSG Ratio}

Estimation of reduced glutathione was done according to [8]. The freezed plant tissue (1.0 g) was homogenized in Trichloroacetic acid (TCA) solution under cold condition. The extract was centrifuged at $15,000 \times \mathrm{g}$ for 10 min at $4^{\circ} \mathrm{C}$. The supernatant was taken in $0.1 \mathrm{M}$ phosphate buffer $(\mathrm{pH}$ 8.0). The $\mathrm{pH}$ was adjusted by adding $5 \mathrm{M}$ $\mathrm{NaOH}$ and $5 \mathrm{M}$ EDTA. The final $\mathrm{pH}$ was recorded at 8.0. The assay mixture contained an aliquot of diluted supernatant, $0.1 \mathrm{M}$ phosphate buffer ( $\mathrm{pH} 8.0)$, and $0.1 \%(\mathrm{w} / \mathrm{v}) \mathrm{O}$-pthaldehyde. The assay mixture was incubated at room temperature for an hour. The fluorescence intensity was monitored at $420 \mathrm{~nm}$ (excitation) and $350 \mathrm{~nm}$ (emission).

For determination of oxidized form of glutathione (GSSG), the extract was diluted with $0.1 \mathrm{M} \mathrm{NaOH}$. The diluted supernatant was incubated with $0.4 \mathrm{M}$ N-ethylmaleimide (NEM) for 30 mins. The mixture was diluted by $0.1 \mathrm{~N} \mathrm{NaOH}$ and adjusted to $\mathrm{pH} 12.0$. An aliquot of the mixture was taken and reacted with same buffer as taken for GSH except $0.1 \mathrm{M} \mathrm{NaOH}$. The fluorescence intensity was monitored at $420 \mathrm{~nm}$ (excitation) and 350 $\mathrm{nm}$ (emission).

The GSH and GSSG ratio were calculated from above data.

\subsection{Biochemical Analysis}

\subsubsection{Assay of Catalase}

Assay of CAT (EC 1.11.1.6) of the sample was done according to [9]. $1.0 \mathrm{~g}$ of tissue was homogenized in 0.5 $\mathrm{mM}$ potassium phosphate buffer ( $\mathrm{pH} 7.0$ ) and and centrifuged at $17,000 \times \mathrm{g}$ for $25 \mathrm{~min}$ at $4^{\circ} \mathrm{C}$. For in vitro assay of CAT, the reaction mixture containing $100 \mathrm{mM}$ phosphate buffer $(\mathrm{pH} 7.0), 10 \mathrm{mM} \mathrm{H}_{2} \mathrm{O}_{2}$ and equivalent amount of protein from enzyme source was added. The activity was determined by reading the decreasing absorbance at $240 \mathrm{~nm}$ (extinction coefficient $0.036 / \mathrm{mM} / \mathrm{cm}$ ). The activity of enzyme expressed as $\mu \mathrm{mol}$ of $\mathrm{H}_{2} \mathrm{O}_{2}$ oxidised/min./mg protein.

\subsubsection{Estimation of Chlorophyll}

The chlorophyll content was estimated according to [10]. The metal treated samples was crushed thoroughly 
with $80 \%$ acetone and were centrifuged at $3000 \mathrm{~g}$ for $10 \mathrm{~min}$ at $4^{\circ} \mathrm{C}$ (Hermle, Model No. Z323K). Supernatant was taken as the source of chlorophyll and was estimated by reading the absorbance at 645 and $663 \mathrm{~nm}$ with a UV-V Spectrophotometer (Cecil, Model No. CE7200).

\subsubsection{Estimation of Glycine Betaine}

Glycine betaine estimation was performed according to [11]. $1 \mathrm{~g}$ of plant sample was finely ground, dried and mechanically shaken with $20 \mathrm{ml}$ of deionized water for 24 hour at $25^{\circ} \mathrm{C}$. The sample was filtered and diluted with $2 \mathrm{~N} \mathrm{H}_{2} \mathrm{SO} 4$ and the filtrate is stored in freezer until analysis. The extract was cooled in ice $(1 \mathrm{~h})$ and reacted with potassium iodide reagent $(0.2 \mathrm{ml})$ followed by vortexing. The sample was kept in $4^{\circ} \mathrm{C}$ for 16 hours followed by centrifugation at 15,000 $\times \mathrm{g}$ for $15 \mathrm{~min}$. the supernatant was taken, dissolved in 1,2-dichloroethane and

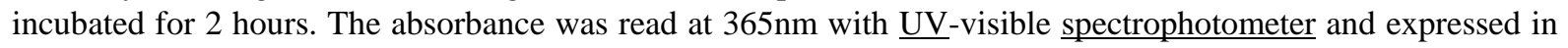
$\mathrm{mg} / \mathrm{g}$ dry mass.

\subsubsection{In Gel Analysis of GPX, CAT and SOD}

For in gel studies of isozymes of GPX, $80 \mu \mathrm{g}$ of protein was run in a non-denaturing $10 \%$ polyacrylamide gel at $10 \mathrm{~V} /$ lane under cold condition [12]. The detection of specific band of polypeptide was resolved in an incubation mixture $50 \mathrm{mM}$ Potassium phosphate buffer, $0.5 \mathrm{mM}$ O-dianisidine and $0.5 \% \mathrm{H}_{2} \mathrm{O}_{2}$.

For in gel studies of CAT [13], $80 \mu \mathrm{g}$ protein was loaded in non-denaturing $10 \%$ polyacrylamide gel at $10 \mathrm{~V} /$ lane under cold condition. Then the gel was incubated in $0.05 \% \mathrm{H}_{2} \mathrm{O}_{2}$ and the bands were developed in solution containing $1 \%(\mathrm{w} / \mathrm{v})$ potassium ferricyanide and $1 \%(\mathrm{w} / \mathrm{v})$ ferric chloride sequentially.

For in gel staining of isozymes SOD [14], $80 \mu$ g of protein was loaded in a 10\% native PAGE which was incubated in two successive buffers: $50 \mathrm{mM}$ sodium phosphate (pH 7.5) with $2.45 \mathrm{mM} \mathrm{NBT}$, then transferred to $50 \mathrm{mM}$ sodium phosphate (pH 7.5) buffer with $26.5 \mathrm{mM}$ TEMED and $26.5 \mu \mathrm{M}$ NBT in dark for $40 \mathrm{~min}$, after that the gel was exposed to fluorescent light for the development of bands.

\subsection{Statistical Analysis}

All the observations were recorded with three replications $(n=3)$ and the statistical analysis was performed by one-way ANOVA analysis, taking $\mathrm{P} \leq 0.05$ as significant. The data in the figures were presented as mean value \pm SE.

\section{Result and Discussion}

From the present experiment, it is found that Marsilea plants are affected with Cd toxicity according to the doses of $\mathrm{Cd}$ as appeared from phenotypic responses. From the observation, a distinct decolorization of leaves was recorded under various Cd concentrations. The plants were achlorophyllous maximum at $200 \mu \mathrm{M}$ of $\mathrm{CdCl}_{2}$ as compared to control $(0 \mu \mathrm{M})$ (Figure 3(b)). The ranges of chlorophyll loss were $21.48 \%$ to $41.18 \%$ through various concentrations of $\mathrm{Cd}$ against control and the loss of chlorophyll, however, was resumed by 1.0505 folds with $2 \mathrm{mM}$ spermidine when compared to highest concentration of Cd (i.e. $200 \mu \mathrm{M}$ ).

From the ongoing results, Marsilea plant showed a distinct loss of its growth and development under ongoing concentration of cadmium (Cd) (Figure 1). Within the stipulated period of experiment, plants, however, recorded to be subdued in some physiological performances. Still, the cellular responses attributing Cd sensitivity or even its tolerance are supposedly to be a bioindication. Therefore, the traits adhered to Cd toxicity for Marsilea needs to be clarified from the viewpoint of hyperaccumulation of heavy metals in such non-vascular plants. Initially, the Marsilea plants responded well to Cd toxicity with its foliage decolorization. Thus, the loss of chlorophyll could be indexed preliminary for Cd sensitivity.

The loss of chlorophyll under heavy metal has already been clarified in relation to both its synthesis as well as turnover. Regardless of plant species the inhibition of the biosynthesis of chlorophyll is related to rate-limiting steps by enzymes under Cd induction [15]. It is evident that the retardation of chlorophyll could be experienced by the non-availability of magnesium (Mg) which is an essential metal for chlorophyll biosynthesis. As already documented in our earlier findings, Marsilea plants may undergo a serious wilting at acute Cd toxicity [16]. Thus, in the present experiment, we studied one of the concomitant effects of Cd toxicity in relation to water potential of plants. Contextually, glycine-betaine, a frequently occurring osmolyte has been found to be overexpressed significantly in Marsilea plant (Figure 3(c)). The elevation of glycine-betaine in a dose-depen- 


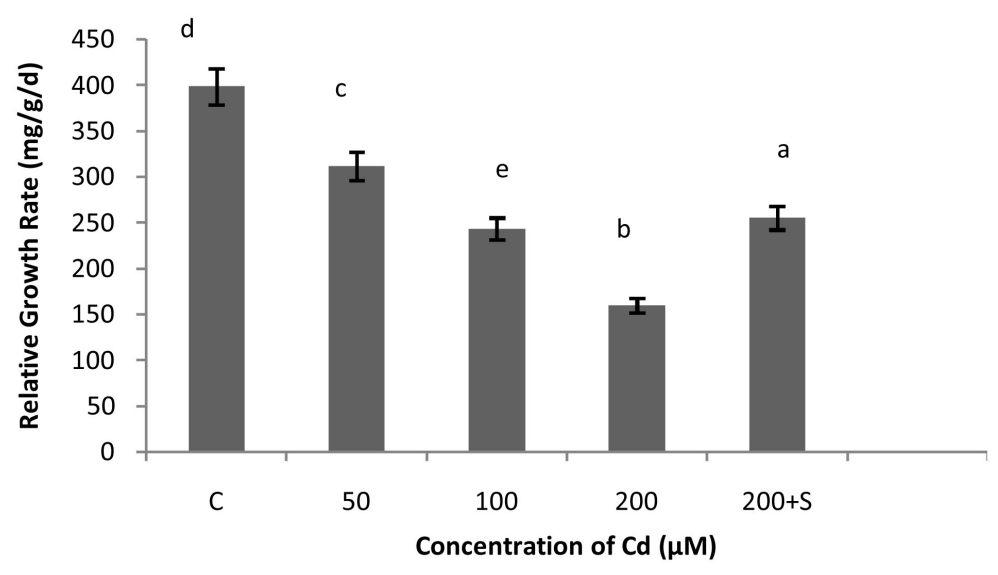

Figure 1. Relaive growth rate (RGR). Effects of varying Cd concentrations (0, $50,100,200 \mu \mathrm{M}$ of $\mathrm{Cd}$ salt) and $200 \mu \mathrm{M}$ of Cd salt with $2 \mathrm{mM}$ Spermidine (200 $\mu \mathrm{M}+2 \mathrm{mM}$ Spd) on growth of Marsilea plant. The data represented as mean value of observations $(n=3) \pm S E$ and put by the vertical bars. Different letters indicate significant differences and similar letters indicate insignificant differences among mean values within each treatment (Student $t$-test, $\mathrm{P} \leq$ 0.05).

dent manner of $\mathrm{Cd}$ as well as with the moderation of Cd undoubtedly is suggestive to involve itself as reliever of osmotic status. The increase in glycine-betaine was in the order of 1.8986 folds, 2.6149 folds and 3.8649 folds under 50, 100 and $200 \mu \mathrm{M}$ of $\mathrm{Cd}$ as compared to control $(0 \mu \mathrm{M})$. It is interesting to note that the elevation of glycine-betaine content was significantly moderated with Spd application by $30.94 \%$ folds against $200 \mu \mathrm{M}$ of $\mathrm{Cd}$. The retardation of chlorophyll accumulation is based on inhibition of enzymes ( $\delta$-aminolevalinic acid dehydratase, ALA dehydratase, protochlorophyllide reductase), non availability of adequate $\mathrm{Mg}^{++}$and $\mathrm{Fe}^{++}$, replacement of $\mathrm{Mg}^{++}$from tetrapyrorrole ring by Cd interference etc. [17]. The loss of chlorophyll accumulation in leaves, correlated with RGR has strikingly drawn the attention for Marsilea plants as suitable of bioindication to Cd. Marsilea plants with its habit in aquatic environment has undergone a serious deficit of water stress that is indirectly evident from glycine-betaine accumulation.

The spermidine in the present experiment has proven its efficacy to stabilize the osmotic imbalances as that of proline and other osmolytes. The interaction of polyamine with other quarternary amines has synergistically operated in the water relation paths of plant and thereby the spermidine may compensate itself for recovery of water stress behaving as osmolyte. In few communications, it is reported that polyamines have emerged as a substitutions of osmolytes or otherwise behaving as any elicitors that reduces the osmotic shock by protecting the cell membrane [18]. Use of polyamine can also alter the cellular permeability for access of more hydration under metal stresses in many crop species. Cadmium being a prooxidant in nature has been encountered in many angiospermic species for its efficacy of ROS generation, induced mechanism of antioxidation as well as evocation of some cellular traits adhered to such oxidative responses. However, to our best of knowledge, the findings of Cd toxicity with reference to analysis of antioxidation pathway, particularly, under interaction with polyamine would be a new citation with reference to Marsilea plant (an aquatic pteridophyte). On account of antioxidation pathways, we have already evaluated the different reactive oxygen intermediates or species to damage the Marsilea plant under stress. In our earlier communication, we have demonstrated the generation of various ROS in Marsilea plant as well as its concomitant mitigation with its application of spermidine. In the present communication, plants had exercised its antioxidation pathway with defolding of its genetic plasticity by differential gene expression. The latter includes the few antioxidation enzymes like superoxide dismutase (SOD), peroxidase (GPX), catalase (CAT). The activity of anti-oxidative enzymes is regarded as most suitable measures to justify the plant's potential under oxidative stress. Cd is a heavy metal undoubtedly proven its potential to induce oxidative stress in plants [19]. Therefore, in the present experiment, we observed a significant variation in GPX and SOD activity in contrast to CAT.

The lysis of superoxide is the first enzymatic antioxidation which initially prevents the oxidative damages of membrane by superoxide. In our earlier communication, a rise of superoxide dismutase activity in vivo was 
studied in the Marsilea plant under cadmium (Cd) stress. This has been more proliferated with the identification of distinct variation in SOD gene expression according to Cd concentration. SOD being a multigene family have been reported to be expressed and separated by native polyacrylamide gel which resolves three distinct bands. Those bands are commonly featured in many crops are adhered to identified sensitivity of copper $(\mathrm{Cu})$, zinc $(\mathrm{Zn})$, magnesium ( $\mathrm{Mg})$, and iron (Fe) isozyme [20]. In the present experiment also a distinct increase in $\mathrm{Fe}$ and Mn-SOD, particularly at highest concentration of cadmium (Cd) $(200 \mu \mathrm{M})$ may clearly be indicative of superoxide sensitivity in Marsilea plant (Figure 4(c)). Any of isoforms of SOD so revealed from the present experiment has also been a selective trait for biomarker study from the cellular responses under cadmium (Cd), more so, when a dose-dependent relationship is obtained other heavy metal induction. Therefore, detoxification of superoxide and its induced efficiencies in Marsilea plants appears to confirm a functional relationship of cadmium toxicity in aquatic species.

Peroxidase (GPX) which is required to lysis the peroxide predominantly $\mathrm{H}_{2} \mathrm{O}_{2}$ is essentially based on electrophilic reactions with the aid of some phenolic residues as guaiacol, in the present case. Thus, in response to Cd mediated oxidative stress, plants display its cellular expression of GPX in regulated manner. From the figures (Figure 4(a)) it appears a quite consistent increase in gene expression for GPX as compared to control under Cd stress as indicative of the fact for Cd detoxification with reference to $\mathrm{H}_{2} \mathrm{O}_{2}$. Unlike angiospermic species GPX appears with only a single band to show its expression when partial purified protein was run on native gel may be scored a possible bioindication for excess of $\mathrm{H}_{2} \mathrm{O}_{2}$ accumulation in the tissues of Marsilea plant and thereby the activity is overexpressed. However, no such significant variation was noted according to concentration gradient of cadmium (Cd) applied to Marsilea. The establishment of GPX activity with a number of isozymic band in crop species might be linked to subcellularly expression of these genes according to plant's genotypic configuration.

To compensate the depleted redox, more towards the oxidised state of the tissues, plants develop some non-enzymatic antioxidants small molecule in nature. Glutathione is the tripeptide that is composed of glutamic acid-cysteine-glycine. This compound with its two alternative forms reduced (GSH) and oxidised (GSSG) is actively involved in scavenging of free radicals. In fact, glutathione is an integral constituent to replenish another major antioxidant, ascorbate in ascorbate-glutathione pathway. In the present experiment, the increase in GSH content (as depicted in GSH:GSSG in Figure 2) is clearly indicative of the fact of plant's oxidative stress under cadmium(Cd). Thus the ranges of glutathione ratio (GSH:GSSG) varied from 1.13 to 1.45 folds as compared to control against cadmium (Cd) concentration. The overaccumulation of ROS, particularly, the $\mathrm{H}_{2} \mathrm{O}_{2}$ is lysed by ascorbate mediated peroxidation by ascorbate peroxidase (APX). In ascorbate-glutathione pathway, the reduced form of ascorbate is replenished by donation of electron from GSH, so that the former could be efficiently acting on $\mathrm{H}_{2} \mathrm{O}_{2}$ [21]. In a steady state pool of GSH and GSSG, interconversion is facilitated by glutathione reductase, the enzyme present with multiple forms however, in subcellular specific way. In a similar way, the activity profile of GR has already been mentioned in earlier communication where Marsilea plant had significantly overexpressed the GR isoforms under metal stress. Therefore, precisely, the decrease in GSH content may be suggestive for bioindication of oxidative stress either by directly scavenging of free radicals and improving the antioxidation pathway through regeneration of ascorbate. In more insight, the behaviour of glutathione in plant system with its decrease under metal stress may be suggestive for phytochelatin biosynthesis, the non-enzymatic protein with high chelating efficiency metal ion. It is more interesting to see that Marsilea plant has responded well with regards to polyamine metabolism to increase the glutathione (GSH) content. This is somehow related to sustain the GSH activity [22].

Catalase, the enzyme which has a similar activity pattern like, peroxidase, however, it does not involve any phenolic derivatives as electron donor. The Marsilea plants are characterised with a clear expression of CAT isozymic profiles as a function of Cd concentration compared to control. Though there recorded no such variation in band numbers but plants could vividly tune the genetic makeup to antagonize the Cd sensitivity with CAT expression. The downregulation of CAT activity as reported in many crop species under metal stress could be explained either impairment of de novo synthesis of the enzyme or the overload of cellular $\mathrm{H}_{2} \mathrm{O}_{2}$, if any, that creates toxicity to denature the proteins [23]. In conext to bioindication the apparent no change of CAT expression to Cd toxicity could thus find hardly any possibility in Marsilea plants. However, the application with spermidine there is some fold increase in CAT expression in the present experiment (Figure 3(a) and Figure 4(b)). This is interesting to support the earlier postulation that deactivation of CAT by overaccumulation of $\mathrm{H}_{2} \mathrm{O}_{2}$ and that could be erased by polyamine application. In an alternative approach to polyamine encountering 


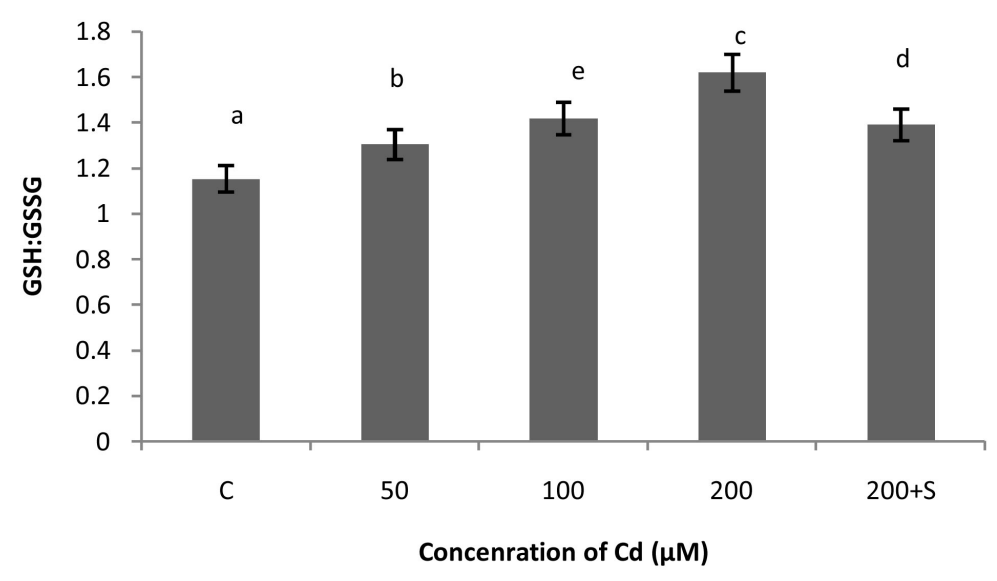

Figure 2. GSH:GSSG. Glutathione (GSH:GSSG) accumulation in Marsilea plant grown under varying concentrations $(0,50,100,200 \mu \mathrm{M})$ of $\mathrm{Cd}$ and 200 $\mu \mathrm{M}$ of $\mathrm{Cd}$ salt suplemented with $2 \mathrm{mM}$ Spermidine $(200 \mu \mathrm{M}+2 \mathrm{mM}$ Spd). The data represented as mean value of observations $(n=3) \pm S E$ and put by the vertical bars. Different letters indicate significant differences and similar letters indicate insignificant differences among mean values within each treatment (Student $t$-test, $\mathrm{P} \leq 0.05$ ).

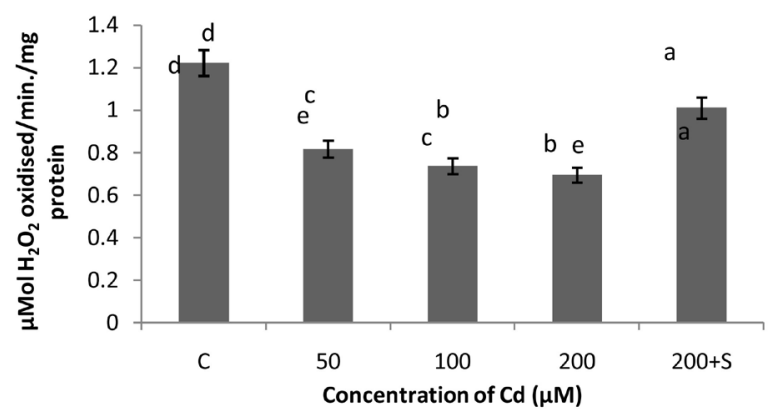

(a)

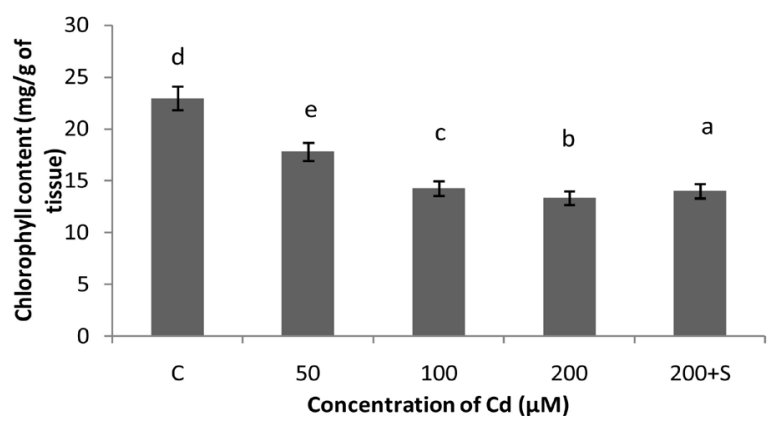

(b)

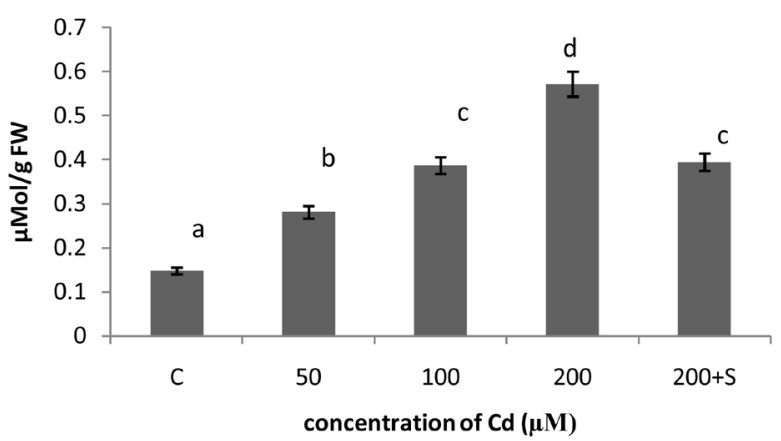

(c)

Figure 3. (a) Changes in activity of Catalase (b) chlorophyll content (c) and glycine betaine content in Marsilea plant grown under varying concentrations $(0,50,100,200 \mu \mathrm{M})$ of $\mathrm{Cd}$ and $200 \mu \mathrm{M}$ of Cd supplemented with $2 \mathrm{mM}$ Spermidine $(200 \mu \mathrm{M}$ $+2 \mathrm{mM}$ Spd). The data represented as mean value of observations $(\mathrm{n}=3) \pm \mathrm{SE}$ and put by the vertical bars in each bar. Different letters indicate significant differences and similar letters indicate insignificant differences among mean values within each treatment (Student $t$-test, $\mathrm{P} \leq 0.05$ ).

the oxidative stress with a threshold concentration of $\mathrm{H}_{2} \mathrm{O}_{2}$ that may not have any impart on CAT denaturation.

From the distribution pattern of dry matter Marsilea plant under interference of Cd toxicity, the allometric analysis of growth was depicted in Figure 1. It clearly shows that plant failed to maintain a steady growth sus- 


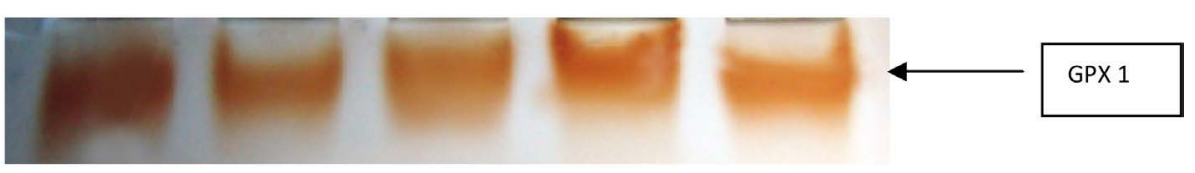

(a) GPX isozymes

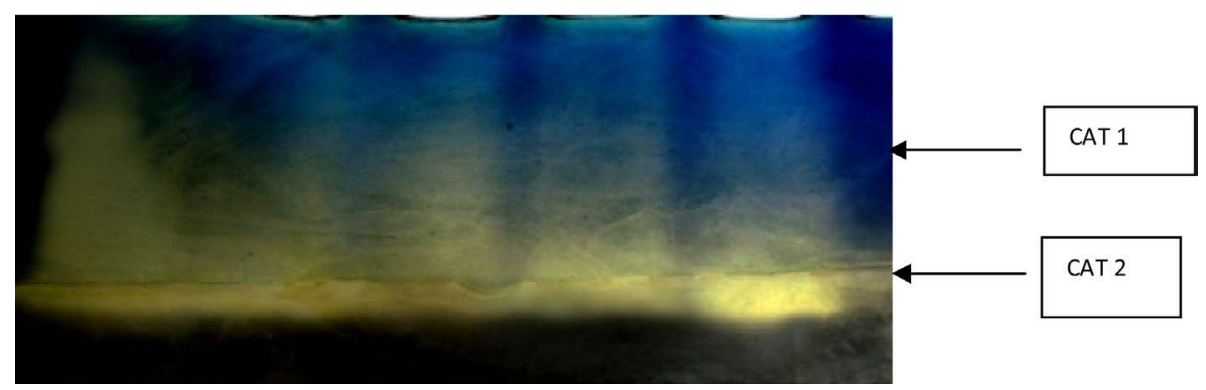

(b) CAT isozymes

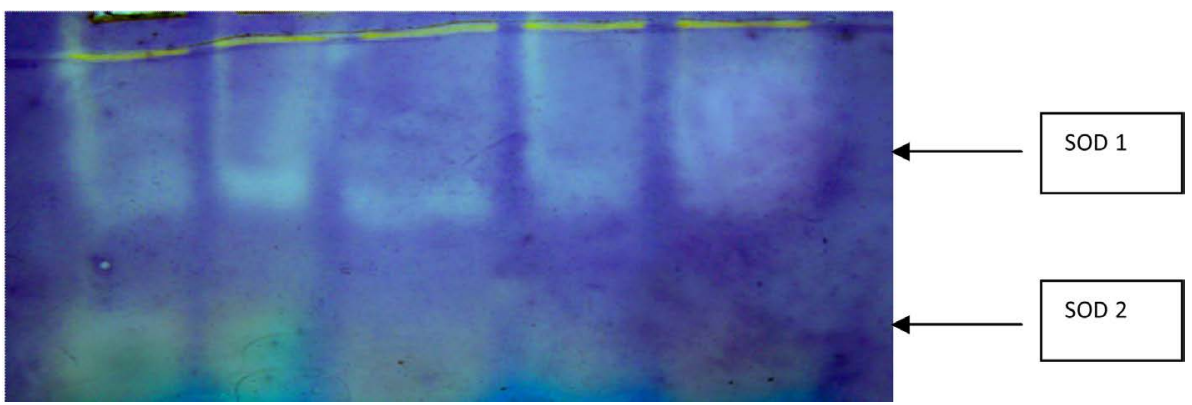

(c) SOD isozymes

Figure 4. Effect of varying concentrations of $\mathrm{Cd}(0,50,100,200 \mu \mathrm{M})$ and $200 \mu \mathrm{M}$ of Cd salt supplemented with $2 \mathrm{mM}$ Spermidine (200 $\mu \mathrm{M}+2 \mathrm{mM}$ Spd) on separation of different isozymes of Guaiacol peroxidase (GPX) (a) Catalase (CAT) (b) and Superoxide dismutase (SOD) (c) on $10 \%$ polyaccrylamide native gel.

tenance according to Cd concentration. The Relative Growth Rate (RGR) value ranges from $21.77 \%$ to 59.83\% decrease as compared to control. However, a significant retrieval of RGR value may be indicative of the fact for sustenance of photosynthetic carbon assimilation and thereby allocations of carbon in different plant parts. Similarly, effect of metal toxicity and thereby its concomitant effect on dry matter accumulation has also been reported in other aquatic macrophytes like Pistia, Lemna etc. [24]. The decline in photosynthetic carbon accumulation out of many related attributing factors like chlorophyll fluorescence, energy depletion and carbon reduction metabolism has been commonly featured in such plants. It reflects plant's non-sustenance under metal even of those studied parameters related to photosynthetic activities somehow could be no less for bioindication of the concerned metal [25]. Still, spermidine may be granted as protecting the cellular membrane stabilizing photosynthetic mechineries and thereby sustaining the carbon acquisition which finally may be supportive for dry matter accumulation. In tropical vegetation, particularly in submerged aquatic condition where illumination becomes a limiting factor for photosynthetic ill performances may be aggravated with different toxic material in aquatic system [26].

\section{Acknowledgements}

This work is financially supported by the DST-PURSE programme activated to Department of Botany, University of Kalyani. The authors are thankful to Prof. Goutam Pal, Dean, Faculty of Science, University of Kalyani, for his scientific comments in preparation of the manuscript.

\section{References}

[1] Sobrino, P.J., Ortega, V.C., Flores, C.M.L., Escobar, C., Del, C.F.F. and Hernández, L.E. (2009) Differential Altera- 
tions of Antioxidant Defenses as Bioindicators of Mercury and Cadmium Toxicity in Alfalfa. Chemosphere, 77, 946-954. http://dx.doi.org/10.1016/j.chemosphere.2009.08.007

[2] Pielichowska, M. and Wierzbicka, M. (2004) Uptake and Localization of Cadmium by Biscutella laevigata, a Cadmium Hyperaccumulator. Acta Biologica Cracoviensia Series Botanica, 46, 57-63.

[3] Feng, R.W., Wei, C.Y., Tu, S.X. and Sun, X. (2009) Interactive Effects of Selenium and Arsenic on Their Uptake by Pteris vittata L. under Hydropronic Conditions. Environmental and Experimental Botany, 65, 363-368. http://dx.doi.org/10.1016/j.envexpbot.2008.11.013

[4] Ma, L.Q., Komar, K.M., Tu, C., Zhang, W.H., Cai, Y. and Kennelley, E.D. (2001) A Fern That Hyperaccumulates Arsenic. Nature, 409, 579. http://dx.doi.org/10.1038/35054664

[5] Mandal, C., Ghosh, N., Dey, N. and Adak, M.K. (2013) Physiological Responses of Salvinia natans L. to Aluminium Stress and Its Interaction with Putrescine. Journal of Stress Physiology \& Biochemistry, 9, 163-179.

[6] Liu, J.H., Nakajima, I. and Moriguchi, T. (2011) Effects of Salt and Osmotic Stresses on Free Polyamine Content and Expression of Polyamine Biosynthetic Genes in Vitis vinifera. Biologia plantarum, 55, 340-344. http://dx.doi.org/10.1007/s10535-011-0050-6

[7] Jampeetong, A. and Brix, H. (2009) Effects of NaCl Salinity on Growth Morphology, Photosynthesis and Proline Accumulation of Salvinia natans. Aquatic Botany, 91, 181-186. http://dx.doi.org/10.1016/j.aquabot.2009.05.003

[8] Hissin, P.J. and Hilf, R. (1976) A Fluorometric Method for Determination of Oxidized and Reduced Glutathione in Tissues. Analytical Biochemistry, 74, 214-226.

[9] Aebi, H. (1983) Catalase in Vitro. Methods in Enzymology, 105, 121-126. http://dx.doi.org/10.1016/S0076-6879(84)05016-3

[10] Arnon, D. (1949) Copper Enzyme in Isolated Chloroplast and Poly Phenol Oxidase in Beta vulgaris. Plant Physiology, 24, 1-7. http://dx.doi.org/10.1104/pp.24.1.1

[11] Greive, C.M. and Grattan, S.R. (1983) Rapid Assay for Determination of Water-Soluble Quaternary Amino Compounds. Plant and Soil, 70, 303-307. http://dx.doi.org/10.1007/BF02374789

[12] Ammar, W.B., Nouairi, I., Zarrouk, M., Ghorbel, M.H. and Jemal, F. (2008) Antioxidative Response to Cadmium in Roots and Leaves of Tomato Plants. Biologia Plantarum, 52, 727-731. http://dx.doi.org/10.1007/s10535-008-0140-2

[13] Baek, S.H., Kwon, I.S., Park, T.I., Yun, S.J., Kim, J.K. and Choi, K.G. (2000) Activities and Isozyme Profiles of Antioxidant Enzymes in Intercellular Compartment of Overwintering Barley Leaves. Journal of Biochemistry and Molecular Biology, 33, 385-390.

[14] Nakano, Y. and Asada, K. (1981) Hydrogen Peroxide Is Scavenged by Ascorbate Specific Peroxidase in Spinach Chloroplasts. Plant and Cell Physiology, 22, 867-880.

[15] Zengin, F.K. and Kirbag, S. (2007) Effects of Copper on Chlorophyll, Proline, Protein and Abscisic Acid Level of Sunflower (Helianthus annuus L.) Seedlings. Journal of Environmental Biology, 28, 561-566.

[16] Das, K., Mandal, C., Ghosh, N., Dey, N. and Adak, M.K. (2013) Cadmium Accumulation in Marsilea minuta Linn. and Its Antioxidative Responses. American Journal of Plant Sciences, 4, 365-371. http://dx.doi.org/10.4236/ajps.2013.42A048

[17] Vassilev, A., Lidon, F.C., Ramalho, J.C., do Céu Matos, M. and Bareiro, M.G. (2004) Bareiro Shoot Cadmium Accumulation and Photosynthetic Performance of Barley Plants Exposed to High Cadmium Treatments. Journal of Plant Nutrition, 27, 775-795.

[18] Kuznetsov, V.V. and Shevyakova, N. (2007) Polyamine and Stress Tolerance of Plants. Plant Stress, 1, 50-71.

[19] Zhao, Y. (2011) Cadmium Accumulation and Antioxidative Defenses in Leaves of Triticum aestivum L. and Zea mays L. African Journal of Biotechnology, 10, 2936-2943.

[20] Borsani, O., Diaz, P., Agius, M.F., Valpuesta, V. and Monza, J. (2001) Water Stress Generates an Oxidative Stress through the Induction of a Specific Cu/Zn Superoxide Dismutase in Loyus corniculatus Leaves. Plant Science, 161, 757-763. http://dx.doi.org/10.1016/S0168-9452(01)00467-8

[21] Pekker, I., Tel, O.E. and Mittler, R. (2002) Reactive Oxygen Intermediates and Glutathione Regulate the Expression of Cytosolic Ascorbate Peroxidase during Iron-Mediated Oxidative Stress in Bean. Plant Molecular Biology, 49, 429-438. http://dx.doi.org/10.1023/A:1015554616358

[22] Mandal, C., Ghosh, N., Maiti, S., Das, K., Gupta, S., Dey, N. and Adak, M.K. (2013) Antioxidative Responses of Salvinia (Salvinia natans Linn.) to Aluminium Stress and It's Modulation by Polyamine. Physiology and Molecular Biology of Plants, 19, 91-103. http://dx.doi.org/10.1007/s12298-012-0144-4

[23] Mandal, C., Ghosh, N., Adak, M.K. and Dey, N. (2013) Interaction of Polyamine on Oxidative Stress Induced by Exogenously Applied Hydrogen Peroxide in Salvinia natans Linn. Theoretical and Experimental Plant Physiololgy, 25, 223-230. http://dx.doi.org/10.1590/S2197-00252013005000004 
[24] Stoeva, V.N. and Bineva, T. (2003) Oxidative Changes and Photosynthesis in Oat Plants Grown in As-Contaminated Soil. Bulgarian Journal of Plant Physiology, 29, 87-95.

[25] Dhote, S. and Dixit, S. (2009) Water Quality Improvement through Macrophytes-A Review. Environmental Monitoring and Assessment, 152, 149-153. http://dx.doi.org/10.1007/s10661-008-0303-9

[26] Tangahu, B.V., Abdullah, S.R.S, Basri, H., Idris, M., Anuar, N. and Mukhlisin, M. (2011) A Review on Heavy Metals (As, $\mathrm{Pb}$, and $\mathrm{Hg}$ ) Uptake by Plants through Phytoremediation. International Journal of Chemical Engineering, 2011, Article ID: 939161. http://dx.doi.org/10.1155/2011/939161. 